\title{
"Mas não somente assim!" Leitores, autores, aulas como texto e o ensino-aprendizagem de História*
}

\author{
Ilmar Rohloff de Mattos ${ }^{* *}$
}

Ao pôr em evidência a "Aula como texto" e seu autor, o professor de História, o artigo possibilita a compreensão das semelhanças e das diferenças entre aqueles que, ao contarem uma história, se tornam historiadores: os escritores da história e os professores de História. Sublinhando o valor do ato de diferentes leituras para a autoria daquela Aula, sublinha-se também a importância de um Texto diferente na formação de novos leitores, aos quais é oferecida, em circunstâncias e situações diversas, a possibilidade de se tornarem autores de novas identidades, construtores da cidadania e de ressignificar a memória.

Palavras-chave: Aula como texto - Ensino-aprendizagem de História - Relação ensino e pesquisas históricas

"But not only like this!" Readers, authors, classes as texts and the History of teaching $\&$ learning

By enlightening the issue of a "Class as a Text" and its author - the history teacher -, this article offers a reflection on different points of view on all those who, when telling some history, become historians: the history writers and the history teachers. As different readings are really worthy to Class authorship, we intend to underline the importance of offering a different Text to the new readers, according to various

\footnotetext{
"Artigo recebido em abril de 2006 e aprovado para publicação em junho de 2006.

** Professor do Departamento de História da PUC/RJ. E-mail: irmattos@his.puc-rio.br.
} 
situations. Also the possibility to become authors of new identities and to construct citizenship and new meanings to the memory.

Keywords: Class as a text - History teaching \& learning - Teaching and History research

“Pas seulement comme ça !" Lecteurs, auteurs, les cours comme texte, l'enseignement et l'apprentissage d'histoire

En mettant en évidence "le cours comme texte" ainsi que son auteur, l'enseignant d'histoire, cet article permet la compréhension des similitudes et des différences entre tous ceux qui deviennent historiens dans l'acte de raconter une histoire : les écrivains d'histoires et les enseignants d'histoire. On met également en évidence la valeur des différentes lectures pour la construction du cours ainsi que l'importance d'un texte différent pour la formation de nouveaux lecteurs, auxquels on offre la possibilité de devenir les auteurs de nouvelles identités, les constructeurs de la citoyenneté ainsi que de conférer autres significations à la mémoire.

Mots-clefs: Cours comme texte - Enseignement/apprentissage d'histoire - Rapports entre enseignement et recherche historique

"Mas não somente assim!"

Dita por alguém que se distinguia por não pouca experiência e muita sensibilidade, a frase preencheu toda a sala e logo se transformou em um convite à reflexão. Pouco importa se a reflexão não era inteiramente nova; nova era a circunstância na qual era proposta, sob a forma de um convite.

$\mathrm{Na}$ sala, realizava-se um "Painel de monografias", ocasião em que aqueles que estão concluindo sua formação como historiadores no nível de graduação apresentam seus trabalhos de final de curso. Às apresentações sucediam os comentários e as observações, que cada um dos presentes entrelaçava de modo particular, ajudando a tecer o painel vivo de uma formação. Apresentações, comentários e observações punham em evidência o ato de escrever uma história; e "assim são autores" - conforme foi sintetizado por alguém - os que então concluíam uma trajetória.

"Mas não somente assim!" Em sua simplicidade, a observação cumpria o papel de recuperar outras práticas e outros espaços, insinuando correspondências não tão simples entre os dois lados de uma formação e as duas faces não necessariamente complementares de um ofício. Desde então, não apenas o trabalho escrito de final de curso deveria esboçar o painel de uma trajetória. A ele correspondia a Prática de Ensino, em diferentes salas de aula e em 
diferentes momentos, complementando o painel. Com efeito, a conclusão da formação do historiador não deve ser outra coisa: por meio de um Texto escrito ou por meio de uma Aula, cada um daqueles que ali se apresentava se mostrava habilitado para contar uma história; fazia História; tornara-se um Autor. Naquele momento, somente a uns poucos a correspondência insinuada pode ter escapado: "Fazer história é contar uma história". O enunciado de uma autoridade historiográfica referendava a observação só aparentemente simples, porque apropriada de um modo singular. Professores e escritores de história contam uma história; ao texto escrito corresponde a aula. Ambos são autores; ambos fazem História. O convite à reflexão estava posto; quase um desafio. Não saberia dizer com certeza se não quis ou não consegui recusá-lo!

Começo retomando a sentença de François Furet: "Fazer história é contar uma história". Não saberia dizer se o historiador francês a enunciara pela primeira vez no já distante ano de 1975. O que é possível dizer é que ele não foi, seguramente, o primeiro a estabelecer uma relação de implicação entre "fazer" e "contar" uma história. Em outras circunstâncias, em tempos diversos, em outras oficinas, outros já o haviam feito, ainda que com intenções provavelmente diversas. Quaisquer que elas fossem, revelavam a inextricável relação entre $\mathrm{o}$ ato de narrar e as diferentes acepções de um mesmo significante: a experiência vivida; seu relato; uma ficção; a explicação erudita.

Todavia, retomo a sentença para pôr em evidência a correspondência entre Texto e Aula, modos diversos de contar uma história. E o faço não apenas para destacar as semelhanças entre ambas as práticas - escrever um texto e dirigir uma aula - mas sobretudo para realçar as diferenças no exercício específico de nosso ofício. Para tanto, sirvo-me, em primeiro lugar, de uma experiência exemplar - a de Capistrano de Abreu no Colégio Pedro II.

Foi em 1883, aos trinta anos de idade, que ele concorrera à cátedra de Corografia e História do Brasil, do Imperial Colégio de Pedro II, com a tese intitulada "Descobrimento do Brasil. Seu desenvolvimento no século XVI". A qualidade do trabalho - no qual se destacava o rigoroso procedimento de método de crítica documental, que em muitos pontos parecia não ter outra finalidade senão sublinhar a crítica feita dois anos antes ao compêndio didático de um dos examinadores, que insistia em datar determinado acontecimento tomando como referência o manual do autor de A Moreninha, "porque Macedo não era fonte, e provar conhecimento de Macedo não era provar conhecimento de fonte" - não apenas lhe garantiria a aprovação. O Descobrimento abria-lhe um 
imenso continente - a História do Brasil -, o que lhe possibilitaria esculpir, ao longo de uma caminhada, a figura do historiador Capistrano de Abreu. Mas, naquele momento e nos anos imediatamente seguintes, o exercício da cátedra afigurava-se-lhe, antes de tudo, como a possibilidade de "quebrar os quadros de ferro de Varnhagen que, introduzidos por Joaquim Manuel de Macedo no Colégio de Pedro II, permaneciam a base do ensino". Assim, ele talvez desejasse que crítica historiográfica e crítica documental de fundo erudito, escrita da história e ensino da história pátria pudessem caminhar juntos, tornando cada um dos estudantes capaz de ler os sinais grafados no grande livro de nossa formação como Nação desde o Descobrimento.

Todavia, o ensino da história pátria o afastaria do colégio, agora denominado Ginásio Nacional, em 1899. A extinção da cadeira de História do Brasil, anexada ao ensino da História Universal, encontraria a oposição daquele que, de acordo com alguns, já era considerado a maior glória do magistério oficial brasileiro. Entre amargo e irônico, diria ter sido "dispensado de alunos ignorantes e desatentos"; provavelmente mais amargo do que irônico, na observação feita quase duas décadas depois.

A experiência é reveladora. Então, contar a história pátria por meio de um texto ou por meio de uma aula não eram recursos entendidos como práticas distintas, razão por que o "historiador" e "a maior glória do magistério oficial brasileiro" se apresentavam como as duas faces complementares de Capistrano de Abreu. Não obstante, os "alunos ignorantes e desatentos" talvez já indicassem, há mais de um século, que o processo de ensino-aprendizagem difere fundamentalmente do processo de pesquisa, porque se o movimento deste é animado por questões e problemas, como o que motivara a tese de Capistrano, o movimento daquele é fruto da contradição entre o velho e o novo, propiciador de desequilibrações sucessivas. Aqui, o novo e o desconhecido são o objeto de ensino que tanto possibilita a ampliação do universo do conhecimento quanto funda a relação entre professores e alunos, uma vez que o novo e o desconhecido se constituem em objeto de ensino e oportunidade de aprendizagem, a um só tempo.

Quando o lente João Capistrano de Abreu passou para a classe dos extintos do magistério oficial, por ter-se recusado a aceitar o aproveitamento como professor da nova cadeira de História Universal, ele não apenas insistia no recorte de um continente - a História do Brasil como disciplina autônoma. Fazia também uma opção: a de apenas contar a História do Brasil por meio de 
um texto escrito. E o fez em Capítulos magistrais. Desde então, a sombra do historiador Capistrano de Abreu projetar-se-ia sobre o lente do Colégio Pedro II. Contudo, sua opção ajuda-nos a melhor compreender nossa própria opção: a de contar uma história por meio de uma aula - ou seja, ser professor de história. Assim, a opção de Capistrano nos diferencia tanto dele quanto daqueles outros que ensinavam história naquele mesmo tempo.

Permaneço ainda por um momento com o historiador cearense, de modo a poder sublinhar uma segunda diferença.

Do "Descobrimento" [a tese de concurso] a "Três séculos depois" [o último dos Capítulos de História Colonial] Capistrano de Abreu esboça a genealogia da Nação brasileira. Dois eixos - tempo e espaço - orientam esta genealogia: o fluir linear e progressivo de um tempo homogêneo é preenchido pela ocupação do território, na qual se destaca o povoamento do "Sertão". A narrativa histórica apresenta-se como o conjunto de acontecimentos singulares, recuperados por rigorosa pesquisa documental, e que encontram o seu lugar em ambos os eixos a partir de um "sentido" ou um "fim" há muito estabelecido - a constituição da Nação brasileira - por aquele que conta uma história. Ao recortar naquela genealogia os "períodos" de uma constituição, Capistrano narra os momentos mais significativos da formação do povo brasileiro, sempre por meio de um texto escrito.

Assim, "fazer história é contar uma história". Retorno a François Furet, pondo em evidência aquela que me parece ser sua intenção principal, no texto de 1975: marcar a diferença entre uma "história-narrativa" (ou "história evenemencial") e uma "história-problema", entre uma forma de contar uma história da qual se afastava - "o que me parece caracterizar a evolução recente da historiografia é o recuo talvez definitivo dessa forma de história, sempre florescente ao nível das produções de grande consumo" - e esta outra forma - a dos "profissionais da disciplina".

Furet se posicionava favoravelmente a um determinado tipo de explicação erudita - a "história-problema" - elaborada por "profissionais da disciplina", em detrimento de uma outra forma de narrativa que, além de sua pretensão de se apresentar como um fiel relato, se distinguia por um "fim" previamente determinado ou um "sentido" preestabelecido. Este pode ser diferente segundo os historiadores e os acontecimentos que escolheram para contar: a apologética religiosa ou a edificação moral; a exaltação do poderio ou da consciência nacional; ou ainda o sentimento do progresso, sob a forma do 
desenvolvimento econômico, do triunfo da razão, da democracia, da liberdade ou da igualdade. Em sua crítica contundente - a qual, ao menos à primeira vista, parecia não valorizar todo o imenso labor daqueles que escreveram o que denomina de "história-narrativa", como foi o caso de Capistrano (observo que a denominação "história-narrativa" me parece pouco feliz) - ele virava as costas para uma forma de narrativa que, na articulação entre passado-presente-futuro, aprisionava não só o futuro, mas também os homens que haviam participado da experiência contada, assim como aprisionava o próprio sujeito que contava uma história, por meio de determinismos diversos.

Mas - e isto é por demais evidente - François Furet não se encontrava sozinho na oficina da qual falava, naquele início do último quartel do século passado. As novas experiências que caracterizavam a modernidade tardia, e que desde então não cessaram de se ampliar e aprofundar, também marcavam fortemente outros historiadores, em que pesem as diferenças entre os mesmos. Ao fim e ao cabo, era a própria oficina da história que se transformava. Experiências que, além de incidirem sobre a própria explicação erudita da história, também se manifestam de modo agudo nas experiências vividas por homens e mulheres em todos os quadrantes. De modo cada vez mais acelerado, deslocam-se os modelos europeus de cultura; os Estados Unidos tornam-se o centro de produção e circulação global de cultura; e a descolonização do Terceiro Mundo faz emergir as sensibilidades descolonizadas. Sob o impacto da globalização e da compressão das dimensões espaço-temporais, os três grandes pilares da identidade e da cultura nacionais - as grandes narrativas da história, da língua e da literatura - são cada vez mais postos em questão. Produzem-se novas identidades, ao mesmo tempo em que novos sujeitos emergem no cenário político e cultural. A abertura para a diferença e o progressivo deslocamento em direção às margens revelam novos atores e autores. Neste mesmo movimento, alguém mais ganha dimensão: o leitor. Desde então, ele não mais se recusa a atribuir sentido aos textos que lhe são oferecidos para leitura, subvertendo mesmo a própria etimologia ao questionar a autoridade do autor. Somente naquele que lê o texto parece se completar plenamente; e um autor em particular já não mais detém o monopólio do texto que produzira, no qual prognosticava o futuro: o historiador. Qualquer que seja o suporte, qualquer que seja a referência dos textos que lhe são oferecidos, é ao leitor que parece caber o papel privilegiado, porque a leitura é sempre apropriação, invenção e produção de significados. E, mais do que nunca, o leitor se mostra capaz de transitar entre o mundo da leitura e a leitura do mundo. 
Como estamos distantes do texto de Capistrano de Abreu! Como a história escrita por um número crescente de historiadores (basta lembrar o papel desempenhado pelos programas de pós-graduação em história, entre nós), nos dias de hoje, é diferente daquela que reserva(va) o lugar central para o Estado nacional. Como leitores, servimo-nos desta distância e desta diferença para atribuir um significado diverso à obra historiográfica de Capistrano de Abreu, avaliando de modo distinto sua grandeza. Como leitores, ainda - mas deixando claro, agora, que leitores somos: professores de história - nos acercamos da frase de Furet, agregando-lhe um sentido diverso - por que não dizer heterodoxo? - que não deixa de encerrar também um certo sentimento de desforra.

Uma leitura singular que revela o fato de os professores de história estarmos imprimindo à nossa prática cotidiana um significado diverso, provocando talvez uma surpresa e rejeitando uma inferioridade. De modo categórico, afirmamos ainda uma vez que, por meio de uma aula, também se conta uma história; que, ao se contar uma história por meio de aula, também se faz história; e que somente ao se fazer história por meio de uma aula nos tornamos professores de história. Por lermos de um modo singular uma proposição, podemos afirmar que também somos autores. Mas o fazemos não para afirmar uma semelhança, e sim para sublinhar a diferença que nos identifica.

É um sentimento de desforra que guarda estreita relação com uma heterodoxia. Ambos não deixam de estar referidos a algo repetido uma infinidade de vezes: "a história começa com a escrita". Uma afirmativa que não apenas atribuía um valor negativo às sociedades ágrafas (elas são a pré-história) como também desvalorizava a memória, apresentada como pobre, confusa e frágil, porque dissociada da escrita. Mas uma afirmativa que associava a história como conhecimento de uma experiência vivida com a prática da escrita, quer porque "sem documentos (em um sentido absolutamente restritivo, documentos escritos) não há história”, quer porque a narrativa historiográfica se concretiza por meio do texto escrito. Entronizava-se, assim, a palavra escrita - e, a partir de determinado momento, a palavra escrita e impressa. Não é necessário retornar aos questionamentos que aquela afirmativa inicial e seus desdobramentos há muito têm suscitado entre os que freqüentam a oficina da história, assim como por muitos outros que se encontram fora dela; mas talvez valha a pena não perder de vista a importância de sempre argüir a respeito do valor e do sentido do ato de questionar. Porque é no ato de questionar a afirmativa de que "fazer história é contar um história" apenas por meio de um 
texto escrito (e impresso) que se situam as condições de uma desforra e de uma heterodoxia. Assim, recusamos uma exclusão, que não raro se desdobrava em um sentimento de inferioridade - os que ensinam história contam uma história, mas não fazem história - para afirmar que os professores de história fazem história por meio de uma aula - a Aula como texto. Um sentimento de desforra e uma heterodoxia que se expressam por meio de uma denominação - a Aula como texto - que a muitos poderá parecer pedante e desnecessária. Guarde-se, porém, que o que ela expressa, antes de mais nada, é a consciência de uma prática; a diferença que nos identifica.

Quer os que se servem de um texto escrito para contar uma história, quer os que o fazem por meio de uma aula parecem ser acompanhados, em seu labor cotidiano, pela indagação que inicia o texto derradeiro e inconcluso de Marc Bloch: "Pai, diga-me lá para que serve a história". A uma indagação que encerra uma inquietação têm sido dadas respostas diferentes, em diferentes momentos e lugares, por diferentes historiadores - isto é, escritores de história e professores de história. Em sua diversidade e multiplicidade, tais respostas revelam que cada um deles sabe por que faz história. E sabe como o faz. É esta mesma indagação inquietante que serve para pôr em evidência a condição de leitor daquele que ensina história; e é esta condição de leitor que lhe permitirá tornar-se autor - autor de uma aula como texto ou, dizendo de outra maneira: é esta indagação inquietante que conduz ao estabelecimento de uma relação específica entre as duas práticas do fazer historiográfico, porque a condição para quem ensina história se tornar um autor reside, antes de tudo, na leitura dos textos dos que escrevem a história, a produção historiográfica. Uma relação mediada pelo ato de ler; mas uma leitura que possibilita a produção do texto de uma aula - embora não ainda a Aula como texto, em sentido pleno. Ele não será jamais a mera repetição ou transcrição do texto lido, e quem o produz sabe disto; assim como sabe que jamais lhe será atribuído o valor do texto escrito e impresso que distingue a obra historiográfica. Não obstante, ele se constitui na condição necessária para revelar um novo autor - o professor de história.

Desde então, os professores de história parecemos seguir a sugestão de um outro escritor, que, em seus romances, parecia, muitas vezes, escrever e reescrever a história do Segundo Reinado, conforme já foi observador por um historiador. "Pode ir buscar a especiaria alheia, mas há de ser para temperá-la com o molho de sua fábrica", sugeria Machado de Assis, pondo em destaque uma inversão intrigante e instigante. 
A "especiaria alheia", isto é, a produção historiográfica, em suas múltiplas referências teóricas e metodológicas e em suas diversas dimensões: livros, artigos, teses, revistas de história de cunho acadêmico e revistas destinadas ao grande público, coletâneas de documentos, cadernos jornalísticos, filmes, vídeos e outros suportes contêm textos que ou apresentam novos problemas, novas abordagens e novos objetos, para retomar uma fórmula francesa por demais conhecida, ou revelam uma abertura para o diferente e um deslocamento em direção às margens. Eles são em número crescente, muitas vezes com uma repercussão que parece ultrapassar as melhores expectativas, conforme $o$ demonstram revistas como Nossa História e a Revista de História da Biblioteca Nacional. Oferecem-se todos à leitura, sem exceção.

As razões por que, como professores, contamos uma história, razões que não são exclusivamente nossas, orientam a busca da "especiaria alheia", as escolhas que fazemos dos textos que se nos oferecem. Uma selę̧ão que começa a dar movimento à relação entre os textos historiográficos disponíveis e a aula de história em processo de produção, de modo a ser ensinada e aprendida. Um movimento que se distingue, no fundamental, por ser um processo de tradução, no qual aquele que traduz(/lê) mais do que nunca se apresenta como um traidor - "tradutor, traidor" - porque a "especiaria alheia", em uma inversão instigante, está sendo temperada "com o molho de sua fábrica". A explicação erudita selecionada e traduzida é transformada no texto de uma aula, a diferença entre ambos os textos caracterizando não apenas uma traição, uma vez que o texto original já não se distingue por sua intenção original, e sim pela intenção de quem o traduziu, mas, sobretudo, assinalando a diferença entre as duas práticas, assim como as razões por que aquele movimento, do qual resulta um produto novo, não mais deverá cessar.

Mas uma seleção e uma tradução que somente ocorrem, e somente devem ocorrer, em decorrência de uma outra relação, que antecede aquelas operações ao mesmo tempo que lhes confere sentido: a relação entre professores e alunos. Uma outra relação que, em seu movimento cotidiano, não cessa de demonstrar o lugar central ocupado pelo aluno; e, por fazê-lo, possibilita que as razões por que contamos uma e o modo como o fazemos se explicitem plenamente - a própria Aula como texto.

Alunos a quem possibilitamos a prática da leitura de um texto - a Aula de história, mas alunos que pouco se assemelham àquela criança que, ao fazer uma indagação inquietante, inaugura o texto de Marc Bloch. Nossos leitores 
são também muito diferentes entre si, porque a escola que freqüentam é muito diferente da de seus avós e talvez da de seus pais; não podendo deixar de se abrir para as diferenças e os diferentes, a escola já não pode pretender reproduzir uma homogeneidade, assim como os textos das aulas de história já não se ocupam com exclusividade da genealogia da nação, como diferentes também são as indagações que nossos alunos fazem, prenhes de outras tantas inquietações. $\mathrm{E}$ em todas estas diferenças reside mais uma das razões - a principal, talvez - por que contamos uma história por meio de uma aula, já que estas diferenças não fazem senão revelar o lugar ocupado pelo aluno na produção de uma aula como texto.

A aula de história como texto é criação individual e coletiva a um só tempo; criação sempre em curso, que permanentemente renova um objeto de ensino em decorrência de novas leituras, de outras experiências vividas, da chegada de novos alunos, dos encontros acadêmicos e das conversas com os colegas de ofício, do surgimento de novos manuais didáticos, das decisões emanadas das instâncias educacionais e das questões, dos desafios e das expectativas geradas pelo movimento do mundo no qual vivemos, em sua dimensão local ou global. Mas o seu renovar permanente é sobretudo o resultado da prática cotidiana do ensino-aprendizagem de nossa disciplina; e porque o professor de história disto tem consciência é que se torna possível a aula como texto. Se a decomponho, lá encontro as narrativas orais ou escritas, os textos dos manuais didáticos que seleciono para leitura, os programas e os planos de curso, os manuais didáticos e os livros paradidáticos, os currículos propostos pelas secretárias de ensino. Os pesos e os valores relativos de cada um destes componentes talvez possam ser avaliados, uma vez dispostos em um continuum que representa a própria Aula, como produto de uma tradução. Ele teria em um dos seus extremos o Texto historiográfico, por ser este sempre o ponto de partida de uma criação e, no outro, a Aula, na qual se destaca o aluno, porque, como já foi mencionado por alguém, desde a Antigüidade, ensinar não é uma função vital, porque não tem o fim em si mesma, a função vital é aprender; assim, neste continuum, os currículos propostos pelas instâncias gestoras da educação estarão sempre mais próximos do primeiro dos extremos, revelando uma "menor" tradução, ao passo que as narrativas orais ou escritas estarão sempre mais próximas do outro extremo, como expressão do "máximo" de tradução. Na aula como texto, ainda, os conteúdos aparecem em uma seqüenciação e gradação; ênfases estão definidas; nela, a narrativa de 
acontecimentos em ordem de sucessão ocupa um lugar e um papel restrito, a importância residindo na narrativa de determinadas durações, cuja explicação e compreensão dependem, em larga medida, dos conceitos históricos com os quais os alunos deverão operar. Ela ajuda a compreender quanto era ingênua a pretensão dos historiadores de controlar o tempo, quanto revela a duração desmesurada do presente no mundo em que vivemos, como que me lembrando que não devo deixar de ter em consideração permanentemente o tempo presente, os homens presentes, a vida presente - conforme já cantara o poeta. Ela é a condição de passagem do velho para o novo conhecimento, por parte dos que aprendem; de superação das explicações da vida social, tributárias do senso comum e de aquisição de uma consciência crítica; e da possibilidade de realização, amanhã, de uma diferente leitura do mundo. Possibilidade de uma prática que se renova a cada dia, a aula como texto ou o texto de nossa aula propicia que cada um dos alunos valorize as diferenças, constitua identidades, crie memórias e exercite a cidadania. E, assim, torne-se capaz de fazer sua própria história.

Mas, certamente, não somente assim!

A observação que preencheu toda a sala, transformando-se em motivação primeira deste texto, foi feita por Selma Rinaldi de Mattos. Com toda certeza, ela a desenvolveria de modo diverso e mais bem fundamentada do que o realizado aqui. O texto de François Furet pode ser encontrado em $A$ oficina da história ${ }^{1}$ tendo sido publicado originalmente em Diogène. ${ }^{2}$ Para traçar as vicissitudes da trajetória de Capistrano de Abreu como professor, assim como recuperar alguns dos juízos e das opiniões por ele emitidos, utilizei os "Capítulos de Capistrano", de minha autoria. ${ }^{3}$ Muito do que é exposto a respeito das relações entre os atos de ler, escrever e contar uma história aproveita a "Apresentação" que fiz de Ler e escrever para contar. Documentação, historiografia e formação do historiador." "Circulando sobre as terras de

\footnotetext{
${ }^{1}$ François Furet, A oficina da história, Lisboa, Gradiva, s/d.

${ }^{2}$ François Furet, "L’Atelier de l'historien”, Diogène, no 89, Paris, 1975.

${ }^{3}$ Ilmar Rohloff de Mattos, "Capítulos de Capistrano", disponível em http://www.historiaecultura.pro.br/modernosdescobrimentos/desc/capistrano/frame.htm.

${ }^{4}$ Ilmar Rohloff de Mattos (org.). Ler e escrever para contar - Documentação, historiografia e formação do historiador, Rio de Janeiro, Access Editora, 1999.
} 
outrem" - as obras de Roger Chartier; A ordem dos livros, ${ }^{5}$ Michel de Certeau, A invenção do quotidiano, artes de fazer, ${ }^{6}$ e Marisa Lajolo, Do mundo da leitura para a leitura do mundo ${ }^{7}$-, pude recolher elementos para falar de leitores e autores. As reflexões instigantes de Stuart Hall em Da diáspora. Identidades e mediações culturais ${ }^{8}$ e em $A$ identidade cultural na pós-modernidade, ${ }^{9}$ assim como as de Walter Mignolo em Histórias locais/Projetos globais. Colonialidade, saberes subalternos e pensamento liminar ${ }^{10}$ ajudaram a traçar o quadro mais geral de transformações fundamentais no qual se situa a oficina da história, hoje. Para as relações entre os dois modos de contar uma história, no processo de ensino-aprendizagem, as quais põem em evidência a tradução da produção historiográfica em história a ser ensinada, foram importantes os trabalhos de Yves Chevallard, La transposition didactique: du savoir savant au savoir enseigné, ${ }^{11} \mathrm{e}$ Vera Teresa Valdemarin, Estudando as lições de coisas. ${ }^{12}$ Todavia, se me propus a aceitar um desafio, em momento certamente de descuido, foi porque sempre soube que poderia me servir da experiência acumulada em algumas décadas como professor, da qual um dos aspectos mais relevantes tem sido a troca cotidiana com alunos e colegas de ofício. Com eles tenho partilhado expectativas e dúvidas, mas, sobretudo, aprendido, embora os equívocos que esta reflexão encerra somente a este autor devam ser atribuídos. Espero que Carlos e Pedro, meus netos que há pouco chegaram mas muito em breve deverão estar ao lado de outros novos leitores, possam um dia aprender com estes professores que, contando histórias por meio de uma aula como texto, contribuem de modo decisivo para a constituição de identidades, a construção da cidadania e a ressignificação da memória. E isto é mais do que suficiente para lhes dedicar este texto.

\footnotetext{
${ }^{5}$ Roger Chartier, A ordem dos livro: leitores, autores e bibliotecas na Europa entre os séculos XIV e XVIII, Brasília, Editora Universidade de Brasília, 1994.

${ }^{6}$ Michel de Certeau, A invenção do quotidiano, artes de fazer, Petrópolis, Vozes, 1994.

${ }^{7}$ Marisa Lajolo, Do mundo da leitura para a leitura do mundo, São Paulo, Ática, 1993.

${ }^{8}$ Stuart Hall, Da diáspora. Identidades e mediações culturais, Belo Horizonte/Brasília, Editora da UFMG/Unesco, 2003. Organização de Liv Sovik.

${ }^{9}$ Stuart Hall, A identidade cultural na pós-modernidade, $10^{\text {a }}$ Edição, Rio de Janeiro, DP\&A Editora, 2005.

${ }^{10}$ Walter Mignolo, Histórias locais/Projetos globais. Colonialidade, saberes subalternos e pensamento liminar, Belo Horizonte, Editora da UFMG, 2003.

${ }^{11}$ Yves Chevallard, La transposition didactique: du savoir savant au savoir enseigné, Grenoble, La pensée sauvage, 1991.

${ }^{12}$ Vera Teresa Valdemarin, Estudando as lições de coisas, Campinas, Autores Associados, 2004.
} 